\title{
THE DEVELOPMENT OF CRYOGENIC METHOD OF DEEP TREATMENT OF INULIN-CONTAINING VEGETABLES (TOPINAMBOUR) AND OBTAINING OF PREBIOTICS IN THE NANOPOWDERS FORM
}

\author{
Raisa Pavlyuk \\ Department of Technology Processing of Fruits, Vegetables and Milk \\ Kharkov State University of Food Technology and Trade \\ 333 Klochkivska str., Kharkov, Ukraine, 61051 \\ ktppom@mail.ru \\ Viktoriya Pogarska \\ Department of Technology Processing of Fruits, Vegetables and Milk \\ Kharkov State University of Food Technology and Trade \\ 333 Klochkivska str., Kharkov, Ukraine, 61051 \\ Vadim Pavlyuk \\ Department of Technology and Organization of Restaurant Business \\ Kharkov Trade and Economics Institute of Kyiv National University of Trade and Economics
} 8 Otakara Jarosha alley, Kharkov, Ukraine, 61045

\section{Katerina Balabai}

Department of Technology Processing of Fruits, Vegetables and Milk Kharkov State University of Food Technology and Trade 333 Klochkivska str., Kharkov, Ukraine, 61051

\section{Svetlana Loseva}

Department of Technology Processing of Fruits, Vegetables and Milk Kharkov State University of Food Technology and Trade 333 Klochkivska str., Kharkov, Ukraine, 61051

\footnotetext{
Abstract

The aim of the work is elaboration of the principally new cryogenic method of deep processing of inulin-containing vegetables (topinambour) using cryogenic "shock" freezing and fine-dispersed comminution and getting of it nanopowders (prebiotics).

There was elaborated principally new cryogenic method of deep processing of topinambour for getting nanopowders - prebiotics. This method differs from traditional ones by the full exclusion of thermal processing of the raw material. Method is based on the use of complex effect of cryogenic "shock" freezing on the raw material using liquid nitrogen, fine-dispersed comminution and sublimation drying. It allows not only preserve biological potential of vegetables but also reveal it more fully and extract the hidden (associated) forms of the low molecular biologically active substances and polymers and transform them into soluble, easily assimilated nanoform.

It was established, that cryogenic method allows more fully extract the low molecular biologically active substances from the state associated with biopolymers in nanocomplexes into free one $(1,8 \ldots 2,3$ times more than in initial raw material). There was revealed mechanism of process, connected with cryomechanodestruction, non-enzymatic catalysis and mechanocracking.

It was revealed, that cryogenic methods allows more fully extract heteropulysaccharides - pectin substances, cellulose and proteins from the form associated in nanocomplexes with other biopolymers (1,3 ...3 times more).

It was established, that cryogenic method of topinambour processing allows partially (by $45 \ldots .55 \%$ ) destruct the difficultly soluble biopolymers such as inulin, pectin substances, cellulose and proteins to their separate monomers in soluble nanoform. There were also revealed conformational changes of molecules of topinambour proteins. It was demonstrated, that form changes and the protein molecule, size of its kernel, coat and ratio of hydrophobic and hydrophilic amino acids remains decrease.

It was demonstrated, that topinambour nanopowders outgo the known analogues of traditional topinambour powders by chemical and disperse composition. It was established that their assimilability is 3 times higher than in traditional ones.
}

Keywords: cryogenic method, inulin, prebiotics, fine-dispersed, cryogenic freezing, nanopowders, nanocomplexes. 


\section{Introduction}

The aim of the work is elaboration of the principally new cryogenic method of deep processing of inulin-containing vegetables (topinambour) using cryogenic "shock" freezing and fine-dispersed comminution and getting of it nanopowders (prebiotics).

In Kharkov state university of food technology and trade (Kharkov, Ukraine) at the department of technology processing of fruits and vegetables in laboratory of innovative cryo- and nanotechnologies of vegetable additives and wellness products together with Kharkov trade and economic Institute of Kyiv national university of trade and economics (Kharkov, Ukraine) was elaborated cryogenic method of the deep processing of topinambour and getting of it nanopowders - prebiotics.

This method differs from traditional ones by the full exclusion of thermal processing of the raw material [1-5]. Method is based on the use of complex effect of cryogenic "shock" freezing on the raw material using liquid nitrogen, fine-dispersed comminution and sublimation drying [6]. It allows not only preserve biological potential of vegetables but also reveal it more fully and extract the hidden (associated) forms of both the low molecular biologically active substances (BAS) and polymers and transform them into soluble, easily assimilated nanoform.

\section{Materials and methods of the study of the low molecular BAS and biopolymers content at elaboration of cryogenic method of deep processing of inulin-containing vegetables}

\section{1. Studied material and equipment used in experimental procedures}

The study was carried out in Kharkov state university of food technology and trade at the department of technology processing of fruits and vegetables and milk (Kharkov, Ukraine).

Cryogenic "shock" freezing was carried out using the modern experimental equipment, especially, cryogenic program freezer with computer support (Fig. 1) that functions using both coolant and inert medium of gaseous nitrogen. Cryogenic program freezer was elaborated in National aerospace university of M. E. Zhukovsky "KAI” (Kharkov, Ukraine) together with joint authors of the article.

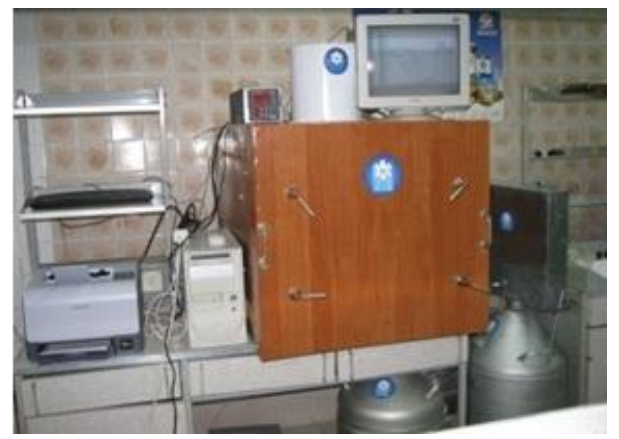

Fig. 1. Cryogenic program freezer with computer support

Cryogenic processing of topinambour samples was carried out at temperature $-60{ }^{\circ} \mathrm{C}$ in the chamber of fast freezing. Topinambour samples were frozen with different speeds $\left(2,5,10,20{ }^{\circ} \mathrm{C} / \mathrm{min}\right)$ to the final temperature in product $-35 \ldots-40{ }^{\circ} \mathrm{C}$. At that, for freezing of $1 \mathrm{~kg}$ of vegetables were used from 0,5 to 1,01 of liquid nitrogen depending on thickness of frozen product. The volume of working chamber on the raw material load was up to $10 \mathrm{~kg}$.

Sublimation vacuum drying was carried out in vacuum sublimation dryer (Fig. 2), produced at the experimental factory of Institute of problems of cryobiology and cryomedicine of National academy of sciences of Ukraine (Kharkov city, Ukraine) and was created for drying of medical preparations, living microorganisms, foodstuff and other biological objects. The drying of samples was carried out at temperature $-20{ }^{\circ} \mathrm{C} \ldots-22{ }^{\circ} \mathrm{C}$, pressure $-10^{-3} \ldots 8 \cdot 10^{-4} \mathrm{~Pa}$ and additional drying at $+50 \ldots+55{ }^{\circ} \mathrm{C}$ (during 30...40 min). Drying was carried out to the final humidity $5 \%$.

Fine-dispersed comminution was carried out in comminutors (especially, in bedded, vibration-bedded mills, attritors of Ukrainian production and cutter-activator (France)) at temperature not higher than $-10{ }^{\circ} \mathrm{C}$ to the particles size in dozens times less than at traditional comminution. 
As objects of the study were used topinambour tubers (Fig. 3) and nanopowders of sublimation drying of them (Fig. 4).

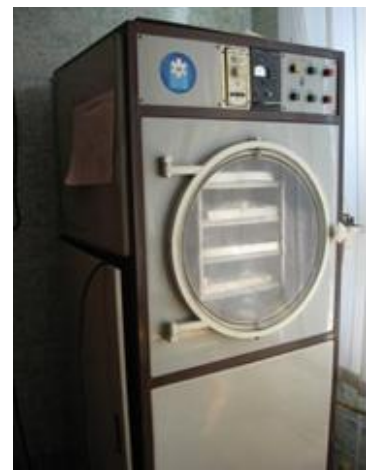

Fig. 2. Vacuum sublimation dryer

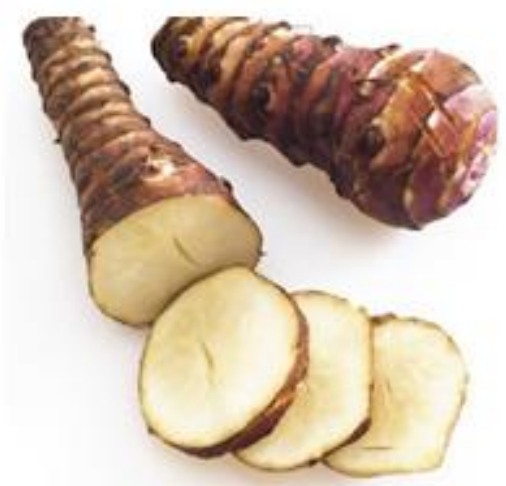

Fig. 3. Initial raw material (topinambour tubers)

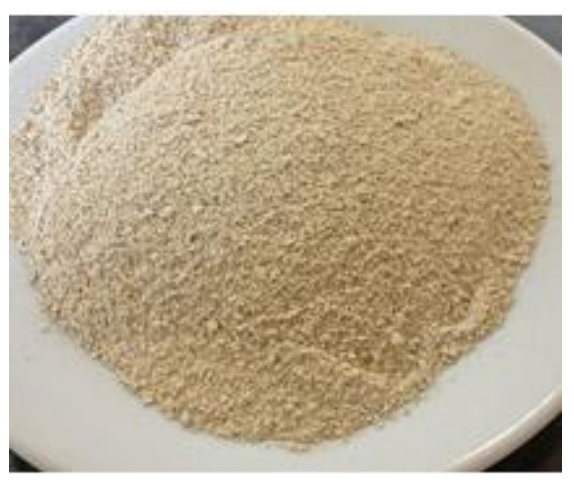

Fig. 4. Nanopowder of topinambour sublimation drying

\section{2. Methodologies of determination of parameters of studied samples}

Criteria of assessment of cryomechanodestruction processes at elaboration of cryogenic method of topinambour processing into the form of topinambour nanopowders were used at determination of chemical substances in vegetable raw material and ready additives, especially:

- protein of associated and free amino acids, hydrophilic and hydrophobic remains of amino acids, inulin, fructose, general pectin, protopectin, soluble pectin substances, cellulose, organic acids and other;

- L-ascorbic acid, low molecular phenol compounds (oxycinnamic acids), flavonol glycosides, catechins, tanning substances.

At the same time the influence of cryomechanodestruction processes was controlled by determination of conformational changes of protein molecules (especially, radius, volume of kernel 
and coat, form of protein molecules and so on) and assimilation degree of additives using bio-testing express-method.

For solving the set problems alongside with commonly used chemical [7-13], physical-chemical [14], spectroscopic [15], chromatographic methods of research [15], were used the original ones, namely: the method of protein structure and conformational changes determination by E. G. Fisher [16, 17] and express-method of biological activity (or assimilability) determination by L. N. Brayenes [18].

As a control sample was used fresh, ripe, washed topinambour of Interest sort, planted in Kharkov region and harvested in autumn (October), stored in the vegetable store house at temperature $+2 \ldots+4{ }^{\circ} \mathrm{C}$. The mean size of topinambour tubers by the largest transversal diameter was $30 \mathrm{~mm}$, and mass - $150 \mathrm{~g}$ (tubers). Experimental procedures were carried out with fivefold repetition. The received results are given in units of CI international system.

Mass fraction of the general nitrogen was controlled by Kjeldahl method [7].

Mass fraction of free and associated amino acids was controlled using chromatographic methods of research (ion-exchanged chromatography) on automatic analyzer AAA 339 (Microtechna-Prague-CSSR) on the base of laboratory of assessment of the of forage and animal production quality in Institute of cattle breeding of National academy of agrarian sciences of Ukraine (Kharkov, Ukraine).

Method of determination of protein structure and conformational changes. The structure of initial raw material proteins and their conformational changes at getting nanoadditives were determined using method, elaborated by Nobel prizewinner Fisher E. G. [16, 17]. This method allows by the known ratio of polar and non-polar remains of amino acids in protein molecule calculate its radius, volume and form and also radius of its kernel and index of kernel filling with hydrophobic remains. Method is based on the fact that all amino acid remains, included in polypeptide chain of protein molecule, can be conventionally divided in two groups: non-polar (hydrophobic) and polar (hydrophilic) ones. In water the flexible molecules curls up in globule. Sphere has a minimal area of surface at given volume. Non-polar remains create within protein fraction the certain likeness of spherical drop and the polar ones are concentrated on its surface. It leads to creation of compact body - globule with hydrophobic kernel and hydrophilic coat.

Method allows determine the molecule form by the general number of amino acid remains in kernel and polar and non-polar remains ratio. Using the method at work the forms of protein molecules of the fresh raw material and topinambour nanoadditives were determined. Methodology of determination of the protein structure and conformational changes of studied samples is presented in the works $[16,17]$.

Biological activity (or assimilability) of samples was determined by original express-method of L. N. Brayenes. The assessment of substances (or product) biological activity was carried out by generative activity (or increase of young forms) of biological test-objects (unicellular infusoria Paramecium caudatum), that is by stimulation of reproduction [9]. The essence of method of control of biological activity (or assimilability) of the different products and substances using infusoria is based on straightening of absorbing and digestive ability of elementary organism - infusoria and activation of their reproduction in the case if studied product includes substances that stimulate their growth and development. At presence of toxic or other harmful substances in tested product there is observed deceleration of development or death of infusoria. Methodology of determination of biological activity of studied samples is presented in the work [18].

Inulin content was determined according to methodical instructions of biochemical analysis. Method is based on inulin property to hydrolyze at presence of hydrochloric or oxalic acid with creation of fructose and also on inulin ability to be dissolved in hot water and not to be dissolved in alcohol. After conducting reaction of neutralization by alkali hydroxide to slightly acid reaction the sugar determination is carried out by the method of Bertran [8]. The difference between percent content of sugars, found after hot extraction with water and 82-percent alcohol will be the sugar, received of inulin.

Mass fraction of pectin substances (general, soluble and protopectin) was measured by the standard weight calcium-pectate method (SSTU 8756.11-70), based on determination of pectin acid content by the mass of calcium pectate, created at interaction of calcium chloride with pectin acid [13]. 
Mass fraction of cellulose was determined by the standard method, based on creation of furfurol of pentosans at cellulose processing by the solution with $13 \%$ mass fraction of hydrochloric acid at heating and determination of skimmed furfurol by spectrofotometric method (SSTU 10820-75) [9].

Vitamin C content was determined by iodometric method, based on oxidizing-renewing reaction that takes place between ascorbic acid and indicator 2,6 - dichlorphenollindophenol (Tillmans paint) (SSTU 24556-89) [10].

Phenol substances content was determined by the method of Folin-Denis in recalculation on chlorogenic acid (SSTU 4373:2005). Method is based on creation of blue complexes at renewal of tungsten acid under effect of polyphenols with Folin-Denis reagent in alkali medium [11].

Polyphenol (tanning substances) content was determined by titrimetic method by tannin (SSTU 24027.2-80). Method is based on the property of tanning substances to oxidize at presence of indigo carmine indicator [12].

Mass fraction of titrated (organic) acids was determined by the method of volume titration (SSTU 25555.0-82). Method is based on neutralization of acids extracts of the studied sample by the alkali solution to the appearance of pink coloration that testifies to the end of reaction [14].

\section{Results of research}

At elaboration of cryogenic method of topinambour processing and getting nanopowders of it using cryogenic "shock" freezing and fine-dispersed comminution it was important to increase the degree of extraction of the hidden forms of BAS associated with biopolymers into free state from the raw material. At the same time it was necessary to partially transform the difficultly soluble polysaccharides, oligosaccharides and proteins into soluble form. It becomes possible at the expense of cryodestruction and cryomechamodestruction and also mechanolysis. It was also important to reveal mechanisms of aforesaid processes and assimilability by the living organisms.

For the first time in international practice authors revealed and demonstrated that at complex action of cryogenic "shock" freezing and fine-dispersed low-temperature comminution on the raw material takes place not also the full preservation of all BAS but also their more full extraction from the raw material. It was demonstrated, that they are in hidden associated forms with biopolymers (proteins, heteropolysaccharides), nanocomplexes and nanoassociates. It was established, that extraction and transformation of BAS into the free state $(1,8 \ldots 2,3$ times more than in the raw material) is connected with mechanocracking. In parallel it was revealed, that at cryoprocessing and fine-dispersed comminution of topinambour takes place destruction of inulin into the separate monomers - fructose by $45 \ldots . .55 \%$, protein - into free acids, cellulose in sugars - by $43 \ldots .55 \%$ at the expense of non-enzymatic biocatalysis - cryomechanolysis [19, 20]. So, there takes place destruction of the difficultly soluble biopolymers and their transformation in easily assimilated nanosized form. The conformational changes of proteins globules were studied. It was shown, that the forms of protein molecule changes, the size of its kernel, coat and ratio of hydrophobic and hydrophilic remains of amino acids and so on decrease. There was also studied the transformation of difficultly soluble heteropolysaccharides, their nanocomplexes together with proteins into soluble easily assimilated form.

It is well-known, that in vegetable raw material (including topinambour) pectin substances are in non-active form and that is why they have the low jelly and absorptive properties $[21,22]$. In this connection were carried out scientific researches when topinambour was frozen using high $\left(2,5,10,20{ }^{\circ} \mathrm{C} / \mathrm{min}\right)$ and low $\left(0,1 ; 0,2 ; 0,5{ }^{\circ} \mathrm{C} / \mathrm{min}\right)$ freezing speeds. The cut tubers were frozen to the different final temperatures in product (especially $-18 \ldots-20{ }^{\circ} \mathrm{C}$ ) and to the lower temperatures in product $\left(-32 \ldots-35^{\circ} \mathrm{C}\right)$ and sublimation drying and fine-dispersed comminution were carried out. In the process of freezing and comminution take place cryomechanodestruction and cryomechanoactivation. It was established, that at complex effect of aforesaid processes on topinambour takes place the more full extraction of pectin from associated state with other biopolymers and nanocomplexes into free active (soluble) form. It was revealed, that there takes place essential degradation and cryodestruction of protopectin and its transformation from non-active form into active (soluble) one. Thus, it was established, that at getting nanopowders of tominambour takes place the more full extraction of pectin substances mass fraction from nano- 
complexes, 3,0..3,4 times more that in initial raw material, including protopectin ( 2 times) and its destruction to the soluble pectin (4,5 times more). In general in topinambour nanopowders $70 \%$ of pectin substances are in soluble form. Mechanism of the more full extraction of pectin substances from nanocomplexes and nanoassociates of the vegetable raw material is connected with their cryomechanocracking (destruction) and non-enzymatic biocatalysis - cryomechanolysis.

Using the method of biotesting of infusoria test-cultures (by generative activity of unicellular organisms) was shown that in comparison with coarsely dispersed topinambour the assimilability of its nanopowders is 2,7...3,0 times higher. It is connected with the higher extraction from the raw material of soluble biologically active and food substances that are in nanosoluble form at fine-dispersed comminution.

It was established, that topinambour additives - nanopowders by chemical composition, BAS content and dispense state exceed the known world analogues, received by traditional technologies. Such technologies are realized at thermal drying at temperature $+65 \ldots+130{ }^{\circ} \mathrm{C}$ and higher, especially, by convective, convective-vacuum, convective-impulse, conductive, vacuum, spraying and other drying methods [23-25]. The significant part of substances (especially, inulin, protein, cellulose, pectin substances) and BAS (phenol compounds, flavonol glycosides, tanning substances) in $60 . .70 \%$ are in nanosized form (Table 1). Thus, for example, difficultly soluble biopolymers (proteins, inulin, cellulose, pectin substances) of topinambour in 45,0..55,0\% were transformed into soluble form as separate monomers (fructose, free $\alpha$-amino acids, glucose, galacturonic acids) that have nanosoluble form. It is known, that the last ones have molecules size from $0,8 \ldots 1,4 \mathrm{~nm}$ $[26,27]$. Nanopowders differ from analogues by the high fructose content (up to 25,0\%) and fructooligosaccharides [23-25]. At the same time they differ by the high content of low molecular phenol compounds (by chlorogenic acid) (up to $2800 \mathrm{mg}$ in $100 \mathrm{~g}$, flavonol glycosides (by rutin) (up to $1800 \mathrm{mg}$ in $100 \mathrm{~g}$ ), tanning substances (up to $2160,0 \mathrm{mg}$ in $100 \mathrm{~g}$ ) (Table 1). The cited compounds have potential immune-modeling, antioxidant, detoxifying and anti-tumor properties [29].

Table 1

Content of biologically active and prebiotic substances in topinambour nanopowders comparing with analogues $(\mathrm{n}=3)$

\begin{tabular}{|c|c|c|c|c|}
\hline Parameter name & $\begin{array}{l}\text { Fresh } \\
\text { topinambour }\end{array}$ & $\begin{array}{l}\text { topinambour } \\
\text { nanopowder }\end{array}$ & $\begin{array}{l}\text { Analogue - topinambour pow- } \\
\text { der of convective vacuum- } \\
\text { impulse (CVI) drying }\end{array}$ & $\begin{array}{l}\text { Analog - topinam- } \\
\text { bour powder of } \\
\text { convective drying }\end{array}$ \\
\hline Inulin, $\%$ & $12,8 \pm 0,5$ & $25,6 \pm 1,5$ & $9,75 \pm 0,1$ & $7,46 \pm 1,3$ \\
\hline Fructose, $\%$ & - & $25,6 \pm 1,5$ & 0,0 & 0,0 \\
\hline Protein, $\%$ & $1,2 \pm 0,01$ & $9,1 \pm 0,2$ & $8,9 \pm 0,1$ & $8,7 \pm 0,1$ \\
\hline Associated amino acids of protein, $\mathrm{mg}$ in $100 \mathrm{~g}$ & 1664,0 & $3698,0 \pm 0,2$ & - & - \\
\hline Free amino acids of protein, $\mathrm{mg}$ in $100 \mathrm{~g}$ & 350,0 & $5415,0 \pm 0,2$ & - & - \\
\hline General pectin, $\%$ & 1,9 & 30,0 & $9,3 \pm 0,1$ & $8,4 \pm 0,1$ \\
\hline Protopectin, \% & 1,2 & 10,4 & - & - \\
\hline Soluble pectin, $\%$ & 0,7 & 23,0 & - & - \\
\hline General sugar, \% & $4,4 \pm 0,1$ & $23,7 \pm 1,4$ & $70,25 \pm 0,2$ & $71,33 \pm 0,2$ \\
\hline Vitamin C, mg100 g & $10,3 \pm 0,1$ & $78,2 \pm 2,4$ & $16,4 \pm 1,1$ & $12,2 \pm 0,3$ \\
\hline $\begin{array}{l}\text { Phenol compounds } \\
\text { (by chlorogenic acid), mg in } 100 \mathrm{~g}\end{array}$ & $350,0 \pm 5,7$ & $2800,0 \pm 12,4$ & - & - \\
\hline Flavonol glycosides (by rutin), $\mathrm{mg}$ in $100 \mathrm{~g}$ & $240,0 \pm 4,8$ & $1800,0 \pm 12,4$ & - & - \\
\hline Tanning substances, $\mathrm{mg}$ in $100 \mathrm{~g}$ & $300,0 \pm 6,4$ & $2160,0 \pm 14,0$ & - & - \\
\hline Ash content, $\%$ & $1,6 \pm 0,1$ & $6,8 \pm 0,2$ & $6,0 \pm 0,2$ & $5,9 \pm 0,1$ \\
\hline Organic acids, $\%$ & $0,3 \pm 0,01$ & $2,0 \pm 0,1$ & $0,8 \pm 0,1$ & $0,65 \pm 0,1$ \\
\hline Humidity, \% & $76,4 \pm 1,2$ & $5,5 \pm 0,1$ & $7,9 \pm 0,1$ & $7,3 \pm 0,1$ \\
\hline
\end{tabular}




\section{Conclusions}

Thus, the use of cryomechanodestruction (cryogenic freezing and fine-dispersed comminution) allows get the qualitatively new feed additives in the form of topinambour nanopowders with record BAS and biopolymers content in easily assimilated nanoform that are impossible to be gotten using traditional methods (convective, convective-vacuum, convective-impulse, conductive, vacuum, spraying and other) of the raw material drying. According to the chemical composition, new feed additives (nanopowders) of topinambour have potential perbiotic, immune-modeling, anti-tumor and detoxifying effects [30]. It is knows, that inulin, pectin substances, cellulose, protein are the indigestive food components, contained in topinambour nanopowders and have prebiotic properties [30]. They stimulate in human organism development and metabolic and biological activity of one or several groups of own bacteria that form intestinal human micriflora, have a positive influence on composition of microbiocenosis. It is also known, that phenol compounds (by chlorogenic acid), flavonol glycosides (by rutin) and tanning substances, contained in topinambour nanopowreds, have potential immune-modeling, antioxidant, detoxifying and anti-tumor effect [28, 30]. In this connection there are reasons to think that nanopowders have the same properties because of containing significant part of these substances.

Experimental data, presented in the article, are the base of elaboration of the cryogenic nanotechnology of topinambour as nanopowders.

New technologies were probated in production conditions of SPE "CRIAS" (Kharkov, Ukraine) and SPE "FIPAR" (Kharkov, Ukraine), the normative documentation was elaborated (TC U 15.3-01566330-304 and TI). On their base were elaborated the new types of wellness products (dry fast soluble fruit nanodrinks «Instant»m dry juices, pastry, new types of nanoicecream, biokefirs, bioyoghurt with prebiotic properties and so on).

\section{References}

[1] Gaukel, V. (2016). Cooling and Freezing of Foods. Reference Module in Food Science, 1-3. doi:10.1016/b978-0-08-100596-5.03415-6

[2] Tu, J., Zhang, M., Xu, B., Liu, H. (2015). Effects of different freezing methods on the quality and microstructure of lotus (Nelumbo nucifera) root. International Journal of Freezing, 52, 59-65. doi:10.1016/ j.ijrefrig.2014.12.015

[3] James, S.J., James, C. (2014). Chilling and Freezing. Food Safety Management, 20, 481-510. doi:10.1016/b978-0-12-381504-0.00020-2

[4] Baláž, P., Baláž, M., Bujňáková, Z. (2014). Mechanochemistry in Technology: From Minerals to Nanomaterials and Drugs. Chem. Eng. Technol., 37(5), 747-756. doi:10.1002/ceat.201300669

[5] Zhao, X., Zhu, H., Zhang, G., Tang, W. (2015). Effect of superfine grinding on the physicochemical properties and antioxidant activity of red grape pomace powders. Powder Technology, 286, 838-844. doi:10.1016/j.powtec.2015.09.025

[6] Yildiz, Y., Nalbant, M. (2008). A review of cryogenic cooling in machining processes. International Journal of Machine Tools and Manufacture, 48(9), 947-964. doi:10.1016/j.ijmachtools.2008.01.008

[7] State Standard ISO 5983-1 (2014). Determination of nitrogen content and calculation of crude protein by Kjeldahl.

[8] GOST 8756.13-87 (1987). Processed fruits and vegetables. Methods for determination of sugars.

[9] GOST 10820-75. (1975). Cellulose. Method for determination of pentosans.

[10] GOST 24556-89 (1989). Products of processing of fruits and vegetables. Methods for determination of vitamin C. Moscow: Publishing House of Standards, 16.

[11] State Standard 4373:2005 (2005). Fruits, Vegetables and products of its processing. Methods for determination of polyphenol content.

[12] GOST 24027.2-80 (1980). Raw medicinal plant. Methods for determination of moisture, ash, extractives and tannins, essential oil. Moscow: Publishing House of Standards, 24.

[13] Ermakov, A., Arasimovich, V., Smirnova-Ikonnikova, M., Murry, I. (1972). Methods of biochemical studies of plants. Moscow: Kolos, 456.

[14] GOST 25555.0-82 (1990). Products of processing of fruits and vegetables. Method for determination of titratable acidity. Moscow: Publishing House of Standards, 15. 
[15] Henshteyn, A., Hupe, K., Lotshpayh, F., Welter, W. (1988). High effective liquid chromatography in biochemistry. Moscow: Mir, 688.

[16] Wolkenshtein, M. (1967). Physic of enzymes. Moscow: Nauka, 199

[17] Pogarskaya, V. (2012). Scientific argumentation of technologies of carotenoid- and chlorophyll-containing fine-dispersed herbal additives: dissertation. Odessa, 502.

[18] Braynes, L., Gorbachev, V. (1997). Determination of activity of apilaka (royal jelly) by biological test. Inform. bulletin about royal jelly (apilak), 4, $37-62$.

[19] Chi, Z.-M., Zhang, T., Cao, T.-S., Liu, X.-Y., Cui, W., Zhao, C.-H. (2011). Biotechnological potential of inulin for bioprocesses. Bioresource Technology, 102(6), 4295-4303. doi:10.1016/ j.biortech.2010.12.086

[20] Klemm, D., Heublein, B., Fink, H.-P., Bohn, A. (2005). Cellulose: Fascinating Biopolymer and Sustainable Raw Material. Angew. Chem. Int. Ed., 44(22), 3358-3393. doi:10.1002/anie.200460587

[21] Ridley, B. L., O’Neill, M. A., Mohnen, D. (2001). Pectins: structure, biosynthesis, and oligogalacturonide-related signaling. Phytochemistry, 57(6), 929-967. doi:10.1016/s0031-9422(01)00113-3

[22] Voragen, F., Beldman, G., Schols, H. (n.d.). Chemistry and Enzymology of Pectins. Advanced Dietary Fibre Technology, 379-398. doi:10.1002/9780470999615.ch33

[23] Yarmosh, L. (2012). A new kind of drying of topinambour. Vestnik KrasSAU, 2, 217-222.

[24] Abramov, Y., Troitskaya, M. (2010). The system of revitalizing energy nutrition. New achievements in chemistry and chemical technology of vegetable raw materials. Barnaul.

[25] Snezhkin, Y., Boryak, L. (1985). Study of dispersion of dry plant materials. Sov. export, 1, 45-47.

[26] Pavlyuk, R., Pogarskaya, V., Pavlyuk, V., Radchenko, L., Yurieva, O., Maksimova, N. (2015). Cryogenic and mechanochemistry in food nanotechnologies: monography. Kharkov: Fact, 255.

[27] Baraboi, V. (1976). The biological effect of plant phenolic compounds. Kiev: Naukova Dumka, 260.

[28] Baraboi, V. (1984). Plant phenols and human health. Moscow, 160.

[29] Korolev, V. (2000). Pharmacology and bases of the plant biochemistry. Kharkov: NPhU, 659.

[30] Kaprelyants, L. (2015). Prebiotics: chemistry, technology and application. Kiev: EnterPrint, 252. 